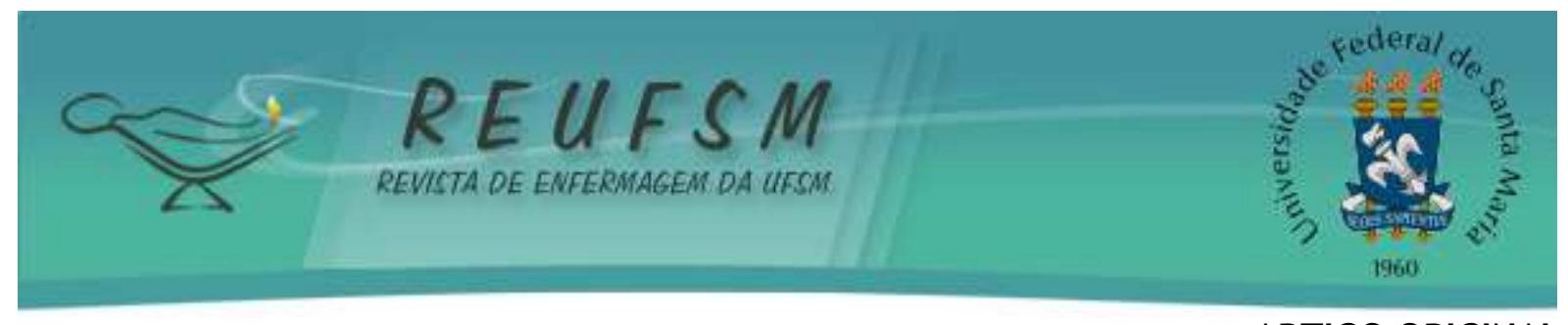

\title{
USO DE MÉTODOS CONTRACEPTIVOS E FATORES RELACIONADOS AO PLANEJAMENTO DA GRAVIDEZ ENTRE PUÉRPERAS
}

\author{
THE USE OF CONTRACEPTIVE METHODS AND FACTORS RELATED TO THE PREGNANCY \\ PLANNING AMONG MOTHERS
}

\section{USO DE MÉTODOS CONTRACEPTIVOS Y FACTORES RELACIONADOS AL PLANEAMIENTO DEL EMBARAZO ENTRE PUÉRPERAS}

\author{
Marcela de Oliveira Alves ${ }^{1}$ \\ Bibiane Dias Miranda Parreira² \\ Flavia Aparecida Dias ${ }^{3}$ \\ Lorena Campos Mendes ${ }^{4}$ \\ Thaís Cristina Elias ${ }^{5}$ \\ Sueli da Silva Riul ${ }^{6}$
}

Doi: $10.5902 / 2179769221249$

RESUMO: Objetivos: descrever o uso de métodos contraceptivos e os fatores relacionados ao planejamento da última gravidez entre puérperas. Método: estudo quantitativo, com 100 puérperas internadas em um hospital universitário do interior de Minas Gerais. Os dados foram coletados por meio de instrumento estruturado, no período de julho e agosto de 2012. Para análise dos dados utilizou-se estatística descritiva e teste qui-quadrado. Resultados: todas as puérperas que planejaram a gravidez eram casadas ou viviam em união estável; dentre aquelas que não planejaram $68,1 \%$ era casada, e 30,6\% solteira $(p<0,001)$. A maioria das puérperas $(59 \%)$ usava algum método anticoncepcional antes da última gestação, com predomínio de injetáveis mensais combinados (67,9\%).Não foram observadas diferenças significativas entre planejamento da gravidez e demais variáveis. Considerações finais: faz-se necessário o preparo dos profissionais de saúde e divulgação de programas que orientem e garantam o direito das mulheres de escolherem o momento ideal para reprodução.

DESCRITORES: Período pós-parto; Anticoncepção; Saúde da mulher; Planejamento familiar.

ABSTRACT: Aim: to describe the use of contraceptive methods and the factors related to the planning of last pregnancy among mothers. Method: quantitative study, with 100 women admitted to a university hospital from the countryside of of Minas Gerais. Data were collected through structured instrument, from July to August 2012. For data analysis descriptive and chi-square test statistic was used. Results: all mothers who planned their pregnancy were married or living in a common-law-marriage; among those who did not plan $68.1 \%$ were married, and $30.6 \%$ single $(p<0.001)$. Most mothers (59\%) used a contraceptive method before their last pregnancy, with a prevalence of

\footnotetext{
${ }^{1}$ Enfermeira. Universidade Federal do Triângulo Mineiro, Uberaba, MG, Brasil, marce_oliveira@hotmail.com

2 Enfermeira. Doutora em Enfermagem. Universidade Federal do Triângulo Mineiro, Uberaba, MG, Brasil, bibianedias@yahoo.com.br

3 Enfermeira. Mestre em Enfermagem. Universidade Federal do Triângulo Mineiro, Uberaba, MG, Brasil, flaviadias_ura@yahoo.com.br

${ }^{4}$ Enfermeira. Mestre em Enfermagem. Universidade Federal do Triângulo Mineiro, Uberaba, MG, Brasil, lorena_camposmendes@hotmail.com

${ }^{5}$ Enfermeira. Mestre em Enfermagem. Universidade Federal do Triângulo Mineiro, Uberaba, MG, Brasil, thaiscelias2@hotmail.com

${ }^{6}$ Enfermeira. Doutora em Enfermagem. Universidade Federal do Triângulo Mineiro, Uberaba, MG, Brasil, sueliriul@terra.com.br
} 


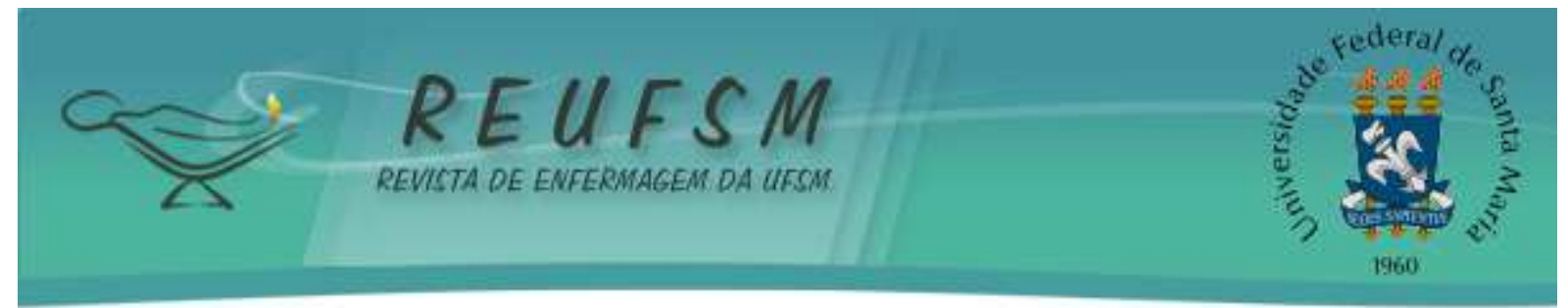

combined monthly injectables (67.9\%). No significant differences were observed between pregnancy planning and other variables. Final thoughts: it is necessary to prepare health professionals and outreach programs to guide and ensure the right of women to choose the optimal time to procriate.

DESCRIPTORS: Postpartum period; Contraception; Woman's health; Family planning.

RESUMEN: Objetivos: describirel uso de métodos contraceptivos ylos factores relacionados al planeamiento del último embarazo entre puérperas. Método: estudio cuantitativo, con 100 puérperas internadas en un hospital universitario del interior de Minas Gerais. Los datos fueron colectados por medio de instrumento estructurado, en el período de julio y agosto de 2012. Para analice de los datos se utilizó estadística descriptiva y teste chi-quadrado. Resultados: todas las puérperas que planearon elembarazo eran casadas o vivían en unión estable; dentro aquellas que no planearon $68,1 \%$ era casada, y $30,6 \%$ soltera $(p<0,001)$. La mayoría de las puérperas (59\%) usaba algún método anticoncepcional antes del último embarazo, con predominio de injertables mensuales combinados $(67,9 \%)$. No fueron observadas diferencias significativas entre planeamiento del embarazo y demás variables. Consideraciones finales: se hace necesarioel preparo de los profesionales de saludy divulgación de programas que orienten y garanticen el derecho de las mujeres de escogierenel momento ideal para reproducción.

DESCRIPTORES: Periodo posparto; Anticoncepción; Salud de la mujer; Planificación familiar.

\section{INTRODUÇÃO}

0 período puerperal constitui-se em um momento de fragilidade, demandando dos profissionais de saúde uma atenção qualificada e holística, focada no contexto sociocultural e familiar e na avaliação dos cuidados dispensados ao trinômio mãecriança-família. ${ }^{1-2}$ Durante o período puerperal, questões relativas ao planejamento familiar são pouco abordadas, sendo que nem sempre é dada a devida importância ao assunto. ${ }^{3}$

Nesse contexto, ressalta-se que o programa de planejamento familiar têm como um de seus objetivos a orientação e o esclarecimento da população quanto aos métodos contraceptivos para que o casal estabeleça o momento ideal, oportuno e desejado para a concepção de um filho, ${ }^{4}$ incluindo-se aqui o período puerperal.

É pertinente repensar como a abordagem dos profissionais de saúde, acerca do planejamento familiar, vem acontecendo, inclusive no puerpério. É importante averiguar se as consultas compreendem as orientações sobre métodos anticoncepcionais e todos os aspectos que envolvem o planejamento familiar, ou simplesmente ocorrem a prescrição da pílula para a prevenção da gravidez indesejada. Sabe-se que a orientação sobre o modo de uso deve ser garantida, pois propõe ao paciente sua própria decisão, após o fornecimento de informações adequadas que garantam uma escolha realmente informada. ${ }^{5}$

0 uso de métodos anticoncepcionais no puerpério deve ser pensado e indicado, considerando-se a importância do intervalo interpartal e do planejamento reprodutivo, visto como uma necessidade e direito das mulheres, neste período específico, ${ }^{6}$ uma vez que, o curto intervalo interpartal configura-se também, como fator de risco para o aborto. ${ }^{7}$ Os profissionais de saúde devem repassar estas informações às puérperas argumentando sobre os benefícios do espaçamento dos nascimentos e formas de planejamento reprodutivo. ${ }^{8}$ 


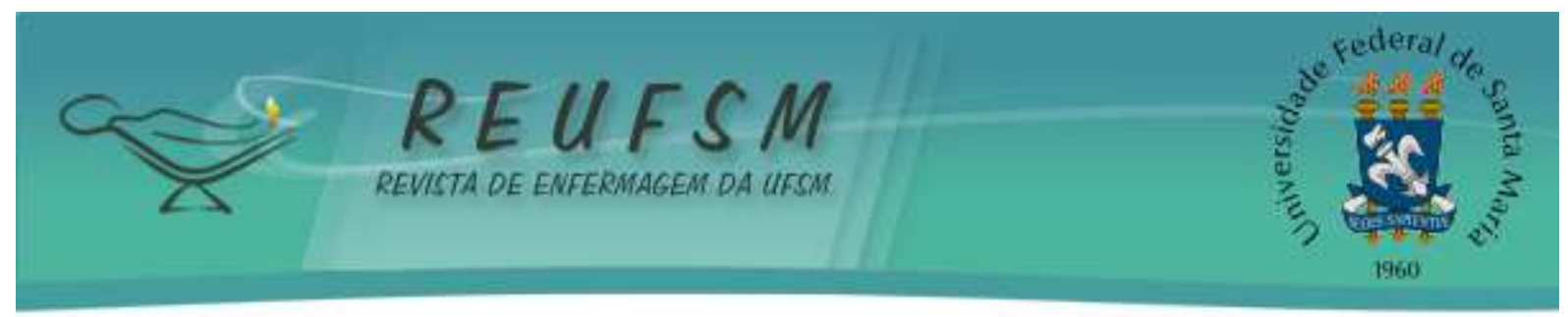

Ao se obervar a ocorrência de gestações não planejadas no cotidiano das práticas de enfermagem na área da saúde da mulher e, buscando-se explicações pertinentes na literatura, indentifica-se uma lacuna de conhecimentos a respeito da maneira como o planejamento familiar vem sendo abordado no puerpério e, sobre como as puérperas utilizam métodos contraceptivos.

Com vistas a conhecer melhor esta realidade, a questão que se colocou para desenvolvimento do presente estudo foi 'como se dá o uso de contraceptivos e planejamento da gravidez entre puérperas atendidas em um hospital público do interior de Minas Gerais e, que fatores podem estar relacionados ao planejamento da gravidez?' Nesse sentido, o presente estudo teve como objetivo descrever o uso de métodos contraceptivos e os fatores relacionados ao planejamento da última gravidez entre puérperas.

\section{MÉTODO}

Trata-se de uma pesquisa transversal e analítica, com abordagem quantitativa. Participaram do estudo 100 puérperas internadas na Enfermaria do Alojamento Conjunto do Setor de Ginecologia e Obstetrícia do Hospital de Clínicas da Universidade Federal do Triângulo Mineiro (EAC/SGO/HC/UFTM), no município de Uberaba/MG. O HC/UFTM é um hospital público, de ensino e, atende aos 27 municípios que compõe a região do Triângulo Sul, exclusivamente ao Sistema Único de Saúde.

Em se tratando de estudo transversal, foram abordadas todas as puérperas admitidas no serviço em questão, durante o período do estudo. Não foi utilizado cálculo para definição de amostra devido ao limitado número de puérperas, sendo necessário abordar todas as mulheres que atendessem aos critérios de inclusão, para se chegar ao maior número possível de entrevistadas, facilitando e conferindo maior credibilidade às informações geradas após o processamento dos dados, caracterizando-se, assim, uma amostragem por conveniência.

O grupo de participantes foi constituído de acordo com os seguintes critérios de inclusão do estudo: puérperas maiores de 18 anos, internadas nas EAC/EGO/HC/UFTM, que estivessem em condições clínicas adequadas de bem estar e estivessem com mais de seis horas de pós-parto, garantindo-se assim o devido repouso de puerpério imediato. Foram considerados critérios de exclusão: apresentar complicações clínicas em decorrência de patologias graves e parto de natimorto.

A coleta de dados ocorreu entre julho e agosto de 2012, sendo esta realizada por meio de entrevista, utilizando-se um instrumento estruturado contendo variáveis sociodemográficas (idade, situação conjugal, escolaridade, ocupação, renda familiar, procedência), história ginecológica, obstétrica e de planejamento da gestação e uso, acesso, dificuldades de obtenção e indicação dos métodos anticoncepcionais. As entrevistas foram realizadas nas enfermarias onde as puérperas encontravam-se internadas, em condição de respeito e privacidade.

Para processamento e análise dos dados, estes foram digitados em planilha eletrônica no programa Microsoft Exce ${ }^{\circledast}$ e, posteriormente importados para o programa Statistical Package for Social Science (SPSS) versão 17.0. Foram utilizadas frequências absolutas e percentuais para as variáveis categóricas e teste qui-quadrado nas associações das categorias entre planejamento da gravidez e as variáveis sociodemográficas $(p<0,001)$.

Este estudo insere-se em um projeto intitulado 'Qualidade de vida e saúde da mulher: análise multifocal', submetido e aprovado pelo Comitê de Ética em Pesquisa com Seres Humanos da Universidade Federal do Triângulo Mineiro, conforme protocolo $\mathrm{n}^{\circ}$ 


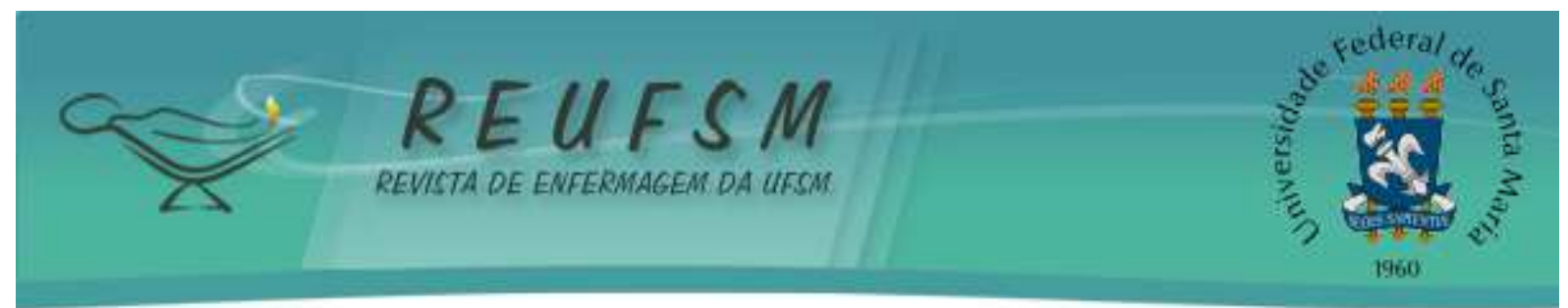

1698/2010. Foram seguidas as normas da Resolução $n^{\circ} 196$ de 10 de outubro de 1996 do Conselho Nacional de Saúde referente à ética em pesquisa com seres humanos. As participantes que concordaram em participar do estudo assinaram o termo de consentimento livre e esclarecido.

\section{RESULTADOS}

Entre as 100 puérperas participantes, identificou-se que a maioria encontrava-se na faixa etária entre 20 a 29 anos (59\%) e era casada ou morava com companheiro (77\%); apenas $22 \%$ eram solteiras. Sobre a escolaridade, $45 \%$ das mulheres tinham de cinco a oito anos de estudo e $45 \%$ possuíam de nove a onze anos. Em relação à ocupação, $63 \%$ referiu não possuir ocupação remunerada, declarando-se do lar e $37 \%$ referiu ocupações remuneradas. Houve predomínio do rendimento familiar de até três salários mínimos (39\%). Quanto à procedência das puérperas, 78\% eram de Uberaba/MG. O HC/UFTM é um hospital de referência para Uberaba e região, por esta razão constatou-se a presença de puérperas de 22 municípios diferentes.

Sobre o início da atividade sexual no grupo estudado, foi constatado que $62 \%$ tiveram sua primeira relação entre os 15 e 19 anos de idade, seguido por $32 \%$ entre 12 e 14 anos. A maioria teve sua primeira gravidez entre 15 e 19 anos (53\%), seguida por 20 e 29 anos (36\%). No que concerne ao número de gestações, $78 \%$ das puérperas tiveram mais de uma, sendo que para $38,5 \%$ das entrevistadas o intervalo entre os partos foi menor que dois anos. Observou-se, ainda, que a maioria das puérperas (72\%) não planejou a gravidez atual. Os dados da Tabela 1 apresentam o uso de métodos anticoncepcionais antes da última gestação. 


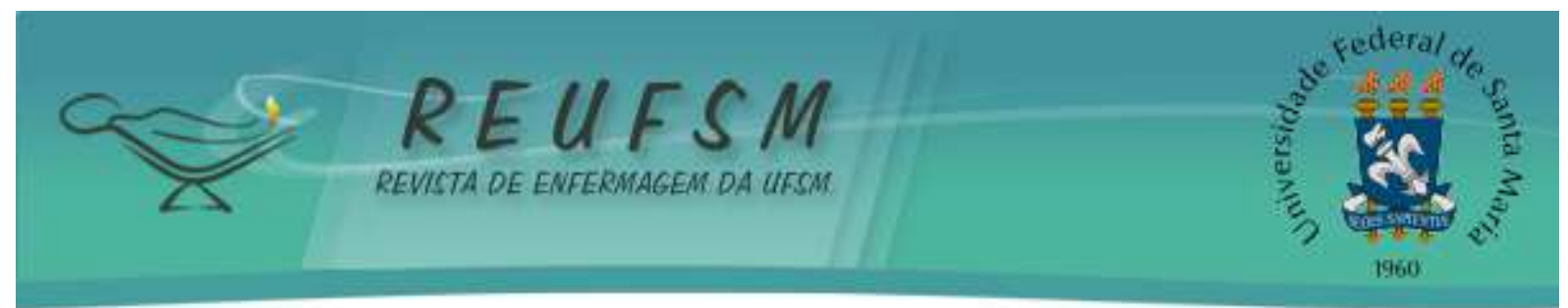

Tabela 1: Distribuição das puérperas segundo o uso de métodos anticoncepcionais antes da última gestação. Uberaba, MG, Brasil, 2012.

\begin{tabular}{|c|c|c|c|}
\hline Variável & & $\mathbf{N}$ & $\%$ \\
\hline \multirow{2}{*}{$\begin{array}{l}\text { Uso antes da última } \\
\text { gestação }\end{array}$} & Sim & 59 & 59 \\
\hline & Não & 41 & 41 \\
\hline \multirow{5}{*}{$\begin{array}{l}\text { Tipo utilizado antes } \\
\text { da última gestação }\end{array}$} & Preservativo masculino & 7 & 11,9 \\
\hline & Dispositivo Intrauterino & 1 & 1,7 \\
\hline & Pílula anticoncepcional & 10 & 16,9 \\
\hline & Ligadura tubária* & 1 & 1,7 \\
\hline & Injetáveis mensais & 40 & 67,8 \\
\hline \multirow{7}{*}{$\begin{array}{l}\text { Motivo por ter } \\
\text { engravidado usando } \\
\text { o método }\end{array}$} & Parou de usar & 19 & 32,2 \\
\hline & Uso errado & 3 & 5,1 \\
\hline & Esqueceu de usar & 5 & 8,5 \\
\hline & Não usou toda vez & 8 & 13,6 \\
\hline & Não sabe & 8 & 13,6 \\
\hline & $\mathrm{Na}$ troca & 15 & 25,4 \\
\hline & Outro & 1 & 1,7 \\
\hline \multirow{7}{*}{$\begin{array}{l}\text { Motivo por não ter } \\
\text { usado }\end{array}$} & Desejo de engravidar & 6 & 14,6 \\
\hline & Não quis usar & 15 & 36,6 \\
\hline & Achou que não iria engravidar & 9 & 22 \\
\hline & Não teve orientação/indicação & 3 & 7,3 \\
\hline & Não sabia qual usar & 4 & 9,8 \\
\hline & $\begin{array}{c}\text { Não tinha problema se } \\
\text { engravidasse }\end{array}$ & 2 & 4,9 \\
\hline & Outros & 2 & 4,9 \\
\hline \multirow[t]{3}{*}{ Aquisição } & Unidade Básica & 12 & 20,3 \\
\hline & Hospital & 1 & 1,7 \\
\hline & Farmácia & 46 & 78 \\
\hline \multirow{2}{*}{$\begin{array}{l}\text { Dificuldade de } \\
\text { conseguir }\end{array}$} & Sim & 2 & 3,4 \\
\hline & Não & 57 & 96,6 \\
\hline \multirow[t]{2}{*}{$\begin{array}{l}\text { Dificuldade em } \\
\text { adquirir }\end{array}$} & $\begin{array}{c}\text { Dificuldade de acesso a serviços } \\
\text { de saúde }\end{array}$ & 1 & 50 \\
\hline & Dificuldade financeira & 1 & 50 \\
\hline \multirow[t]{4}{*}{ Indicação do uso } & Médico & 38 & 64,4 \\
\hline & Parentes & 1 & 1,7 \\
\hline & Farmacêutico & 2 & 3,4 \\
\hline & Ninguém & 18 & 30,5 \\
\hline
\end{tabular}

Fonte: Dados dos autores (2012). 


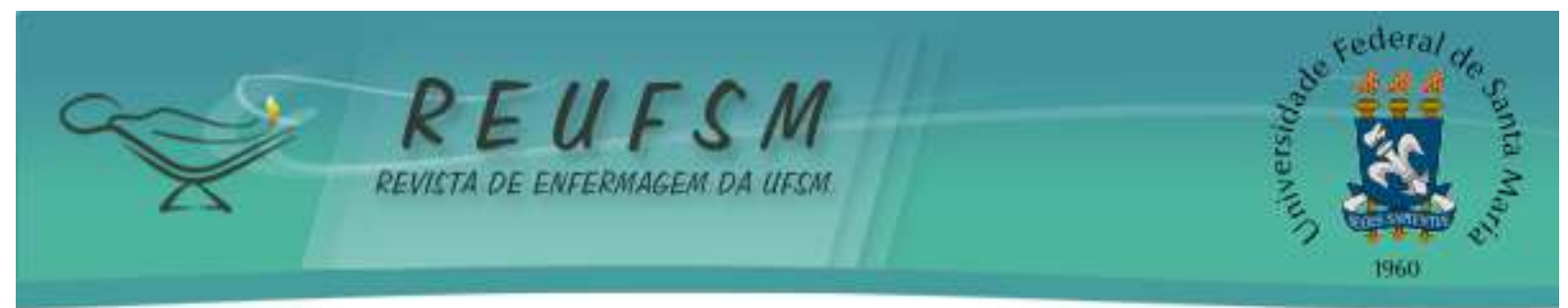

*Note-se que uma puérpera informou ter realizado ligadura tubárea antes da última gestação. Em questionamento estabelecido com a própria, a mesma esclareceu que ao realizar a cirurgia já se encontrava grávida, sem sabê-lo.

De acordo com os dados apresentados na Tabela 1, verificou-se que a maioria das puérperas (59\%) usava algum método anticoncepcional antes da última gestação, com predomínio de injetáveis mensais combinados $(67,8 \%)$. O principal motivo de ter engravidado foi descontinuar o uso do método (32,2\%), seguido pela troca do método anticoncepcional hormonal $(25,4 \%)$.

Entre as 41 puérperas que relataram não usar nenhum método anticoncepcional antes da última gestação, o principal motivo foi não querer usar (36,6\%), seguido por achar que não iriam engravidar (22\%).Com relação ao local de aquisição do método utilizado, a maioria relatou que comprava em farmácias (78\%) e tinha facilidade de adquirir; para as duas puérperas que referiram dificuldades, os motivos foram acesso aos serviços de saúde (50\%) e condições financeiras( $50 \%)$.

Quanto à indicação do uso do método, o médico apareceu como a principal fonte $(64,4 \%)$; no entanto, destaca-se que 30,5\% das entrevistadas referiu que 'ninguém' havia recomendado a utilização do método contraceptivo. Os dados da Tabela 2 demonstram a associação das variáveis sociodemográficas com o planejamento da gestação.

Tabela 2: Associação de características sociodemográficas e planejamento da gestação entre puérperas atendidas pelo SGO/HC/UFTM. Uberaba, MG, Brasil, 2012

Planejamento da gestação

\begin{tabular}{|c|c|c|c|c|c|c|}
\hline \multirow[b]{2}{*}{ Variáveis } & \multicolumn{2}{|c|}{$\operatorname{Sim}(n=28)$} & \multicolumn{2}{|c|}{ Não $(n=72)$} & \multirow[b]{2}{*}{$x^{2}$} & \multirow[b]{2}{*}{$p$} \\
\hline & $\mathbf{N}$ & $\%$ & $\mathbf{N}$ & $\%$ & & \\
\hline \multicolumn{7}{|c|}{ Faixa etária (em anos) } \\
\hline $18+20$ & 3 & 10,7 & 6 & 8,3 & 0,150 & 0,928 \\
\hline $20+30$ & 16 & 57,1 & 43 & 59,7 & & \\
\hline 30 e mais & 9 & 32,1 & 23 & 31,9 & & \\
\hline \multicolumn{7}{|c|}{ Escolaridade (em anos) } \\
\hline $1 \vdash 5$ & 2 & 7,1 & 4 & 5,6 & 2,654 & 0,265 \\
\hline 5 ㅇ 9 & 9 & 32,1 & 36 & 50,0 & & \\
\hline 9 e mais & 17 & 60,7 & 32 & 44,4 & & \\
\hline \multicolumn{7}{|l|}{ Estado civil } \\
\hline Casada & 28 & 100 & 49 & 68,1 & 17,646 & $<0,001$ \\
\hline Separada & - & - & 1 & 1,4 & & \\
\hline Solteira & - & - & 22 & 30,6 & & \\
\hline \multicolumn{7}{|l|}{ Procedência } \\
\hline Uberaba/MG & 20 & 71,4 & 58 & 80,6 & 0,979 & 0,323 \\
\hline Outras & 8 & 28,6 & 14 & 19,4 & & \\
\hline \multicolumn{7}{|c|}{$\begin{array}{l}\text { Renda Individual (em salários } \\
\text { mínimos) }\end{array}$} \\
\hline 1 & 3 & 10,7 & 9 & 12,5 & 4,453 & 0,348 \\
\hline 2 & 3 & 10,7 & 8 & 11,1 & & \\
\hline 3 & 9 & 32,1 & 30 & 41,7 & & \\
\hline 4 & 12 & 42,9 & 17 & 23,6 & & \\
\hline 5 & 1 & 3,6 & 8 & 11,1 & & \\
\hline \multicolumn{7}{|l|}{ Profissão } \\
\hline Do lar & 17 & 60,7 & 46 & 63,9 & 0,087 & 0,768 \\
\hline
\end{tabular}




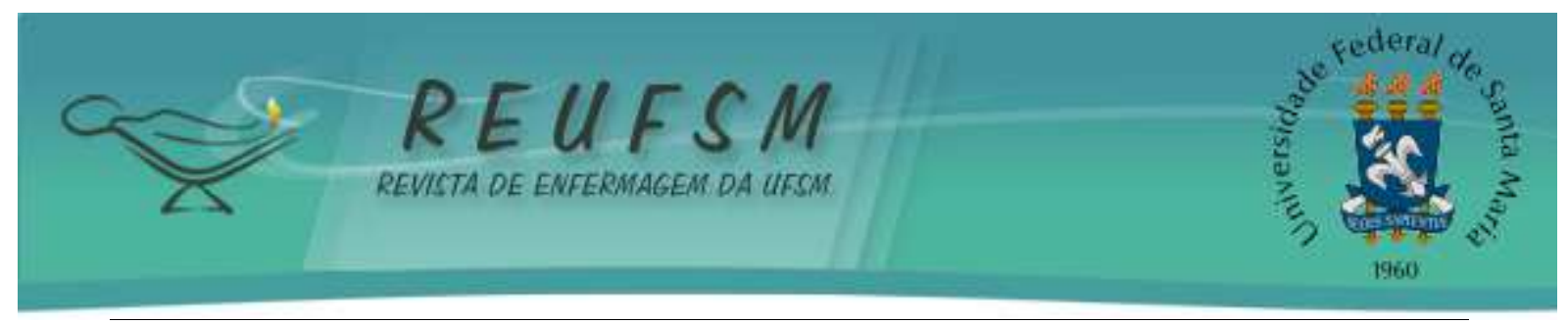

$\begin{array}{lllll}\text { Trabalho remunerado } & 11 & 39,3 & 26 & 36,1\end{array}$

Fonte: Dados dos autores (2012).

Evidencia-se, na Tabela 2, que todas as puérperas que planejaram a gravidez eram casadas ou viviam em relacionamento estável; dentre aquelas que não planejaram 30,6\% eram solteiras $(p<0,001)$. Não foram observadas diferenças significativas entre 0 planejamento da gravidez e as demais variáveis sociodemográficas, ginecológicas e obstétricas.

\section{DISCUSSÃO}

De acordo com os resultados descritos, a maioria das puérperas tinha de 20 a 29 anos, era casada ou vivia em união consensual, possuía de cinco a 11 anos de estudo, não possuía ocupação remunerada e declarou ser do lar, sendo o rendimento familiar de até três salários mínimos.

A maioria das participantes teve o início da atividade sexual e a sua primeira gestação entre os 15 e 19 anos de idade. Estudos similares mostram um início de vida sexual ativa cada vez mais precoce entre as jovens, o que pode contribuir para a falta de preparo para o planejamento reprodutivo. ${ }^{9}$ Nesse contexto, faz-se necessária a participação de familiares, da escola e de campanhas voltadas à prevenção de doenças sexualmente transmissíveis e orientação relacionada às gestações indesejadas, atuando dessa forma, na promoção da saúde e bem estar dos jovens. ${ }^{10}$

Das 100 mulheres entrevistadas, 78\% tiveram mais de uma gestação,tendo tido experiências com métodos contraceptivos após o parto. Esta inferência baseia-se no fato de ter sido verificado, neste estudo, que a maioria $(61,5 \%)$ teve intervalo superior a dois anos entre a gestação anterior e a última. Tal recomendação é verificada na literatura, visto que existem riscos relacionados ao intervalo interpartal curto tanto para a criança como para a mãe. . $^{811}$

Ao comparar a falta de planejamento gestacional (72\%) observada neste estudo com a de estudo desenvolvido em Salvador/BA, evidencia-se aproximação dos resultados, uma vez que a prevalência da gravidez não planejada naquele foi de $66,5 \%$ do total de 191 entrevistadas. ${ }^{12} \mathrm{Em}$ estudo realizado com 358 puérperas no município de Uberaba/MG, $65,6 \%$ não planejou a gravidez atual. ${ }^{13}$

Note-se que, as mulheres continuam engravidando sem planejamento, até mesmo aquelas com maior renda, idade e escolaridade. Pode-se levantar explicações associadas a uma 'falha' na contracepção, podendo ser apontados como exemplos o desconhecimento, dificuldade de acesso ou uso inadequado dos métodos. ${ }^{13}$

Ao se tratar das entrevistadas que usavam algum método anticoncepcional, observase que, diferentemente do que foi identificado neste estudo, uma pesquisa desenvolvida no município de São Gonçalo do Amarante/CE destacou o uso dos anticoncepcionais orais e do preservativo como os métodos contraceptivos mais utilizados entre as usuárias de um serviço de planejamento familiar. ${ }^{14}$ Ainda, verifica-se que, muitas vezes, as mulheres têm sua escolha restrita à anticoncepção adequada devido à indisponibilidade de diversos métodos contraceptivos aprovados pelo Ministério da Saúde, comprometendo assim a sua livre escolha. ${ }^{15}$

O principal motivo atribuído pelas puérperas para a ocorrência da gravidez foi a descontinuidade do uso do método, podendo-se dizer seguramente que fatores, como a falta de informação sobre seu uso, pode contribuir para a este desfecho. Um estudo realizado na cidade de Pelotas/RS demonstrou que apesar de a maioria das mulheres 


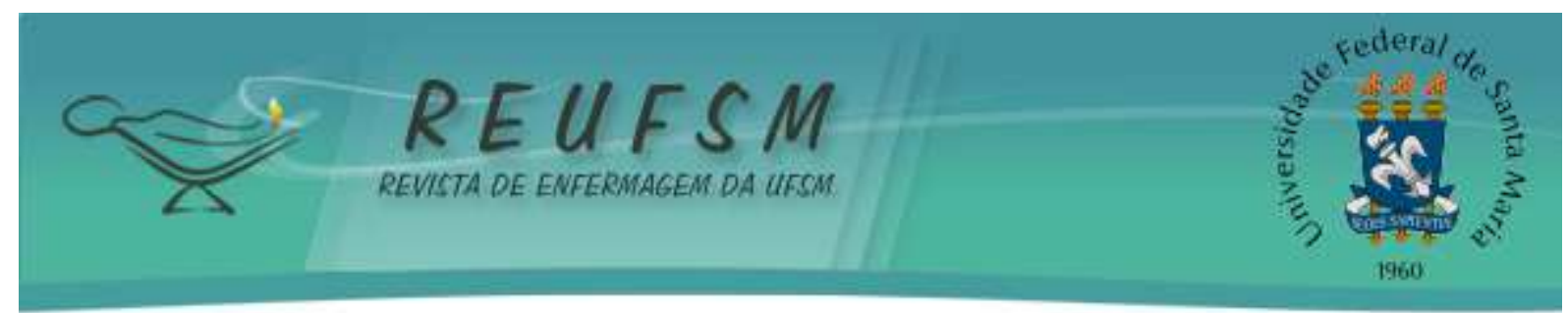

$(86,9 \%)$ declararem conhecimento sobre o uso do anticoncepcional oral, grande parte delas (70\%) não sabia como agir após o esquecimento de um comprimido. Além disso, o preservativo masculino foi apresentado como um dos métodos sobre o qual $30 \%$ da população não possuía informações de uso correto. ${ }^{16}$

Em estudo realizado na cidade de Sousa/PB, com 25 mulheres que engravidaram sem planejamento, foi evidenciado que as principais causas da gravidez não planejada relacionam-se ao uso inadequado dos métodos contraceptivos. Os motivos envolveram a ausência de conhecimento ou conhecimentos errôneos sobre a utilização, o desconforto relacionado ao método selecionado e a indisponibilidade de contraceptivos na unidade de saúde da família na qual as usuárias são atendidas. ${ }^{17}$ Sobre o local de aquisição do método, pode-se dizer que as pessoas ainda encontram dificuldades de acesso aos de serviços de saúde, utilizando medicamentos por conta própria, desprovidas de orientação técnico/científica.

Quanto à relação entre o planejamento da última gravidez e as variáveis sociodemográficas, no presente estudo foi evidenciada associação entre a situação conjugal e a ocorrência de gravidez, pois o grupo das casadas/união estável constituiu $68,1 \%$ das mulheres que não planejaram a gestação. Já entre as 28 que planejaram, 100\% declararam-se casadas/união estável. Nenhuma solteira declarou ter planejado a gravidez. Dados semelhantes foram encontrados em estudo realizado em Salvador/BA, quando os autores verificaram a associação entre situação conjugal e gravidez não planejada, identificando-se uma maior chance entre as mulheres solteiras de engravidarem sem planejamento quando comparadas com as casadas/união estável. ${ }^{12}$

Com relação à idade das respondentes e o planejamento da gestação, foi observado um maior número de mulheres que não planejou a gestação em todas as faixas etárias. 0 mesmo ocorreu com a escolaridade, sendo que mesmo entre as mais escolarizadas, com nove anos e mais de estudo, a maioria não planejou a última gestação. Estes dados contrapõem-se a achados da literatura em que foi possível observar que, quanto mais jovens e com menor renda familiar são as mulheres, maior é a associação com a gravidez não planejada. ${ }^{18}$ Além disso, verificou-se que as adolescentes estão expostas a maiores chances de gravidez não planejada. A maior ocorrência de gravidez não planejada está entre aquelas com até o $5^{\circ}$ ano de ensino fundamental incompleto. ${ }^{12} \mathrm{Na}$ associação entre renda familiar e planejamento da gestação, verificou-se que entre as que planejaram a gestação, a maior frequência $(42,9 \%)$ aparece para aquelas com rendimento familiar de quatro salários mínimos mensais, ou seja, entre aquelas com melhor renda mensal.

A temática relacionada ao planejamento familiar de puérperas remete a importância do retorno à vida sexual de forma segura e a preocupação da mulher com sua saúde reprodutiva. No entanto, observa-se que a atenção das mulheres, neste momento, está mais relacionada à saúde neonatal. Tal fato pode ser verificado em uma pesquisa realizada no município de Santa Cruz do Capibaribe/PE, que buscou identificar motivos que favoreceram o retorno de mulheres à consulta pós-parto, sendo encontrados como principais justificativas a busca pelo bem estar do filho, o sentimento de gratidão pelos profissionais que prestaram atendimento e o acolhimento recebido durante o pré-natal. Antes de qualquer outra prioridade, as mães referiram a preocupação com o bem estar dos filhos, não aparecendo no depoimento dessas mulheres a intenção de uso de um método anticoncepcional ideal para o período. ${ }^{19}$

Ao considerar-se o papel educativo dos profissionais de saúde, observa-se que ainda são pouco frequentes as orientações sobre métodos anticoncepcionais no pré-natal. Seja nas consultas, seja nos grupos educativos as questões referentes à anticoncepção, especificamente no período puerperal, não são adequadamente valorizadas. Tal fato deve ser levado em consideração, pois o papel dos profissionais de saúde seria o de orientar as 


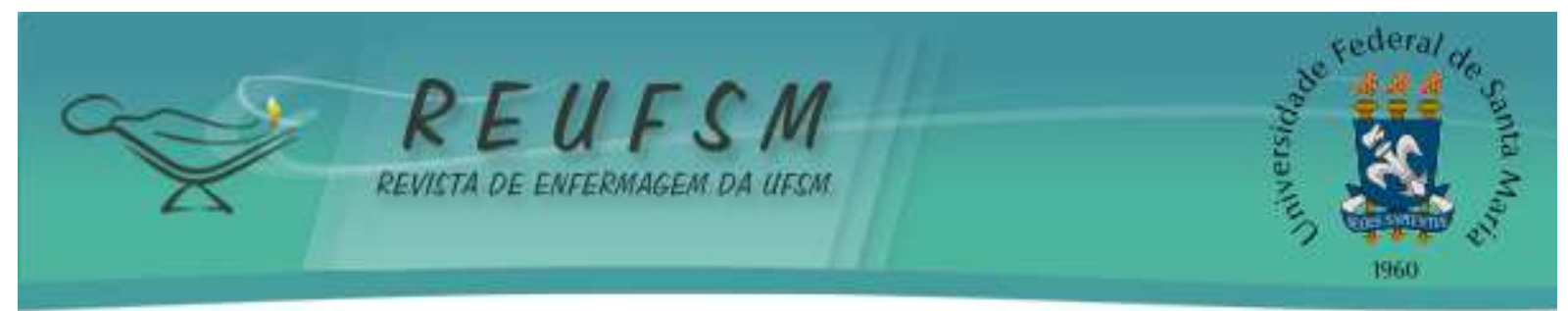

mulheres sobre as opções de métodos contraceptivos específicos para esse período, bem como orientar sobre como deverão ser utilizados e onde poderão ser adquiridos, proporcionando a escolha informada e adequada e, assim, contribuir para a garantia dos direitos reprodutivos das puérperas. ${ }^{20}$

\section{CONSIDERAÇÕES FINAIS}

Entre as puérperas participantes do estudo, a maioria encontrava-se na faixa etária entre 20 a 29 anos, era casada, apresentava cinco ou mais anos de estudo, declarava-se do lar e tinha renda familiar de até três salários mínimos. Além disso, a maioria dessas usava algum método anticoncepcional antes da última gestação, com predominância do uso de anticoncepcionais injetáveis, sendo estes métodos adquiridos em farmácias e indicados por médico.

Evidenciou-se, nesse estudo, que a maioria das participantes não planejou a última gestação, mesmo aquelas mais escolarizadas, com maior renda familiar e idade. Houve associação entre planejamento da gravidez e ser casada ou viver em relacionamento estável.

A orientação quanto à contracepção no puerpério é fundamental, já que a gravidez não planejada pode trazer repercussões que representam riscos para a saúde materna e infantil. Seria importante que se deixasse claro, antes do momento da alta hospitalar, as opções ideais para a anticoncepção no período puerperal.

Observa-se a necessidade de capacitação dos profissionais de saúde e a divulgação de programas que orientem e garantam o direito das mulheres de escolherem o momento ideal para o planejamento reprodutivo, evitando o aumento do número de gestações não planejadas. Espera-se com esse estudo demonstrar a problemática da falta de planejamento reprodutivo e a importância de melhor valorizar ações educativas referentes a essa temática.

Há que se apontar como limitação do estudo, o fato de ser um recorte transversal, baseado no relato pontual das entrevistadas. Seria oportuno que se ampliasse o estudo no sentido de se construir um seguimento às mulheres, identificando no seu cotidiano as dificuldades de acesso e uso de métodos contraceptivos no puerpério.

\section{REFERÊNCIAS}

1. Andrade RD, Santos JS, Maia AC, Mello DF. Fatores relacionados à saúde da mulher no puerpério e repercussões na saúde da criança. Esc Anna Nery Rev Enferm.2015;19(1):181-6.

2. Vieira F, Bachion MM, Salge AKM, Munari DB. Diagnósticos de Enfermagem da NANDA no período pós-parto imediato e tardio. Esc Anna Nery Rev Enferm.2010;14(1):83-9.

3. Santos JC, Freitas PM. Planejamento familiar na perspectiva do desenvolvimento. Ciênc Saúde Colet. 2011;16(3):1813-20.

4. Leventhal CL, Barbosa KSF. Planejamento da gestação entre puérperas de hospital público e privado. RBPS. 2008;21(4):269-74.

5. Fagundes MG, Pires TMS. Planejamento familiar: perfil das usuárias de uma unidade de saúde de Curitiba. Rev Bras Med Fam Comunidade. 2011;6(21):230-8.

6. Parreira BDM, Silva SR, Miranzi MAS. Intenção de uso de métodos anticoncepcionais entre puérperas de um hospital universitário. Rev RENE. 2011;12(1):150-7. 


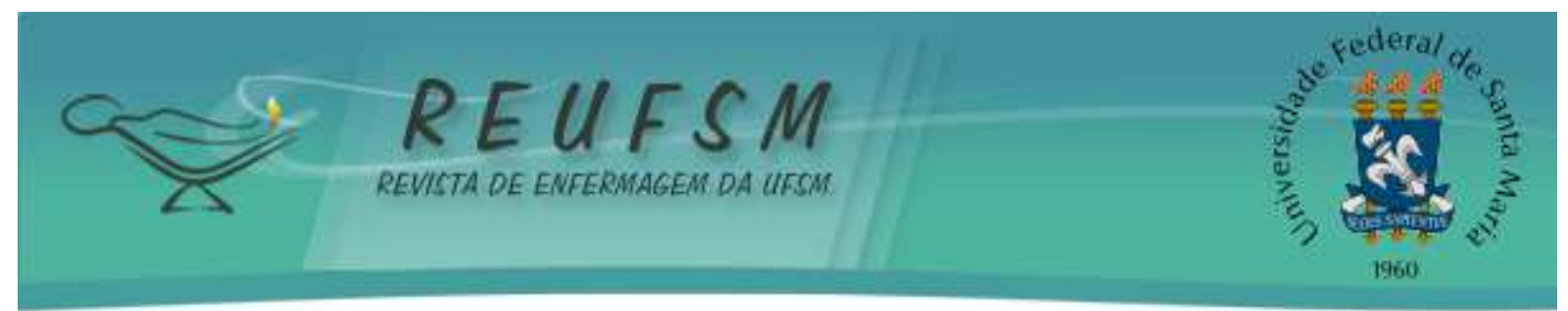

7. Costa CBJSC. Aborto provocado e sua interface com a gravidez não planejada [dissertação]. Fortaleza (CE): Departamento de Enfermagem/Universidade Federal do Ceará; 2012. 72 p.

8. Rutstein SO. Effects of preceding birth intervals on neonatal, infant and under-five years mortality and nutritional status in developing countries: evidence from the demographic and health surveys. Int J Gynecol Obstet. 2005;89 Supl 1:7-27.

9. Dias EG, Alves JCS, Viana M, Santos IM, Silva JP. Percepções sobre a gravidez em um grupo de adolescentes grávidas do município de Janaúba-MG. Rev Eletrônica Gestão \& Saúde. 2015;6(2):1239-53.

10. Hugo TDO,Maier VT, Jansen K, Rodrigues CEG, Cruzeiro ALS, Ores LC, et al. Fatores associados à idade da primeira relação sexual em jovens: estudo de base populacional. Cad Saúde Pública. 2011;27(11):2207-14.

11. Conde-Agudelo A, BelizánJM. Maternal morbidity and mortality associated with interpregnancyinterval: crosssectional study. BMJ. 2000;321(9):1255-9.

12. Coelho EAC, Andrade MLS, Vitoriano LVT, Souza JJS, Silva DO, Gusmão EM, et al. Associação entre gravidez não planejada e o contexto socioeconômico de mulheres em área da Estratégia Saúde da Família. Acta Paul Enferm. 2012;25(3):415-22.

13. Parreira BDM. Práticas contraceptivas de puérperas atendidas em um hospital universitário [dissertação]. Uberaba (MG): Universidade Federal do Triângulo Mineiro; 2009. 112 p.

14. Teles LMR, Silva SS, Eduardo KGT, Moura ERF, Damasceno AKC. Atenção em anticoncepção oferecida por equipe de PSF em São Gonçalo do Amarante-CE. Rev Eletrônica Enferm. 2010;12(4):711-8.

15. Queiroz INB, Santos MCFC, Machado MFA, Lopes MSV, Costa CCC. Planejamento familiar na adolescência na percepção de enfermeiras da estratégia saúde da família. Rev RENE. 2010;11(3):103-13.

16. Paniz VMV, Fassa AG, Silva MC. Conhecimento sobre anticoncepcionais em uma população de 15 anos ou mais de uma cidade do Sul do Brasil. Cad Saúde Pública. 2005;21(6):1747-60.

17. Diniz ERS, Guedes MSE, Oliveira SHS, Silva MLN, Farias EC. Gravidez não planejada em mulheres que participam de um grupo de planejamento familiar. FIEP Bulletin.2011;81 Ed Esp:342-8.

18. Prietsch SOM, Chica DAG, Cesar JA, Sassi RAM. Gravidez não planejada no extremo Sul do Brasil: prevalência e fatores associados. Cad Saúde Pública. 2011;27(10):1906-16.

19. Angelo BHB, Brito RS. Consulta puerperal: o que leva as mulheres a buscarem essa assistência? Rev RENE. 2012;13(5):1163-7.

20. Parreira BDM, Silva SR, Miranzi MAS. Métodos anticoncepcionais: orientações recebidas por puérperas no pré-natal e puerpério. Cienc Cuid Saúde. 2010;9(2):262-8.

Data de recebimento:: 24/02/2016

Data de Aceite: 21/09/2016

Autor correspondente: Sueli Riul da Silva

E-mail: sueliriul@terra.com.br

Endereço postal; Rua Donaldo Silvestre Cicci, 665, Uberaba/MG. CEP 38082-166. 